\title{
LANDFILLS VOLUME INCREASE WITH REINFORCED SOIL EMBANKMENTS: BASIC THEORY AND CASE STUDIES
}

\section{Daniele Cazzuffi ${ }^{1, *}$ and Piergiorgio Recalcati ${ }^{2}$}

${ }^{1}$ CESI SpA, via Rubattino 54, 20134 Milano, Italy

${ }^{2}$ Tenax SpA, via dell'Industria 17, 23897 Viganò (LC), Italy

Article Info:

Received:

7 January 2021

Revised:

12 April 2021

Accepted:

14 April 2021

Available online:

7 June 2021

Keywords:

Geosynthetic

Landfill

Embankment

Reinforcement

Volume increase

\section{ABSTRACT}

The construction of controlled landfills, either for municipal or industrial wastes, is currently acknowledged worldwide as a "social need". Indeed, today one of the main societal issues is the identification of an optimal means of disposing of the huge quantities of urban and industrial waste produced on a daily basis by individuals and factories. The task of environmental engineers is to design landfill systems capable to prevent any pollution to the water, the air, and the surrounding fauna and human life. In densely populated countries, the first problem to be solved is the location of the landfill. This social confrontation often leads to locate the landfill not in most geologically and geotechnically suited site, but in marginal areas which finally satisfy all the fighting communities. More and more geosynthetics are used to solve the problems associated with landfills located in marginal areas. The use of geogrids to construct steep reinforced embankments with the aim to increase the volume of wastes that can be disposed and at the same time to increase the stability of the wastes themselves, is getting more and more diffused. The paper describes the use of geosynthetics reinforced soil structures to increase the landfill volume with reinforced soil embankments. Some examples of structures already constructed, either for industrial or municipal wastes landfills, are described.

\section{INTRODUCTION}

The construction of controlled landfills, either for municipal wastes or for industrial wastes, is aknowoldeged as a "social need". Today, one of the main social issues problems is the identification of the optimal way of disposing of the huge quantity of urban and industrial waste produced daily by individuals and factories. Possible solutions vary among incineration, chemical and/or biological and/or mechanical treatments, burial in soil, or other special technologies. Whichever is the selected solution, at the end of all treatments there is always a fraction of the original waste that remains in the status of marginal or exhausted material.

The final destination of this material is the disposal in a technologically managed landfill. The task of environmental engineers is to design sustainable landfill systems able to prevent any pollution to the water, the air, and the surrounding fauna end human life, taking also into account of an adequate design of the capping (i.a. Cazzuffi \& Recalcati, 2018, Grossule \& Stegmann, 2020).

In densely populated countries, the first problem to be solved is the location of the landfill, since the NIMBY syndrome (Not In My Back Yard) is often the reason for harsh discussions between adjacent communities.

This social confrontation often leads to locate the landfill in a site that is not he most geologically and geotechnically suited; marginal areas which finally satisfy all the fighting communities are chosen. Environmental engineers are therefore challenged by new problems, which often require an interdisciplinary approach, where geologist, geotechnical engineers, chemists, landscape architects and other experts are involved.

Volume increase of the sites chosen for the landfill or in already existing landfill represents a good solution, provided that this choice is done without bringing any hazard to the stability of the amount of wastes. More and more geosynthetics are used to solve the problems associated with landfills located in marginal areas. The use of geogrids reinforced steep embankments to increase the volume of wastes and at the same time to increase the stability of the wastes is diffused. The first examples were mainly consisting in a single, high embankment containing the wastes; recently construction of superimposed embankments is becoming common, as this technique presents advantages from a logistic point of view, as shown later on. 


\section{GEOGRID REINFORCED SLOPES AND EM- BANKMENTS}

\subsection{Basic theory of reinforced soil}

The reinforced soil technique is a construction method developed for thousand years, and has experienced different types of reinforcing materials, from bamboo to steel strips, from tree branches to geogrids. The latest types of reinforcement have the advantage of providing greater durability, strength, proven experience and finally a more theoretical design approach.

The first reinforcement application of geogrids in Europe dates about 1981, while the first use of geogrids in Italy dates back to 1986, when a reinforced embankment was built to contain wastes in a landfill in Modena (Northern Italy), as described by Cazzuffi et al. (1993).

Reinforced soil is a composite material which combines the typical resistance of two different materials in such a way to minimize the weakness of each one. Particularly, a relatively large quantity of the cheapest and compression resistant material, the soil, is improved in its engineering characteristics by the combination with a relatively small quantity of a more expensive and high tensile resistant material, the geogrids. A synergy between the tensile and compressive resistance of the two materials develops, improving the global characteristics of the composite material, as it happens when concrete is associate with steel in reinforced concrete. When geogrids are placed in the soil and the latter is compacted, the soil particles interlock with the grid apertures, which produce a very efficient confining action, thus limiting the relative movements and increasing the shear resistance of the soil-geogrid composite.

The main advantages of a reinforced soil structure are the following:

- lower global cost: steeper slopes reduce the quantity of fill material; moreover, less valuable and cheaper materials can be used;

- improved stability: the reinforcement guarantees an improvement in the factor of safety, even in seismic areas; - possibility to build directly on low-bearing-capacity soils without a preliminary consolidation and great caution during construction.

\subsection{Steep Slopes Analysis: Internal, External and Global Stability}

For steep reinforced slopes, there are three failure modes (Figure 1):

- Internal, where the failure plane passes through the reinforcing elements

- External, (failure surface passes behind and underneath the reinforced mass)

- Compound-Global (failure surface passes behind and/ or through the reinforced soil mass)

Design is based on modified versions of the classical limit equilibrium slope stability methods.

\subsection{Use of geogrids reinforced steep slopes in land- fills}

The technology of geogrid reinforced slopes finds a natural and diffused application in the construction or in the enlargement of controlled landfills, as emphasized also by Cancelli \& Cazzuffi (1994). Among several cases of embankment built to retain wastes in a landfill, it is worth mentioning a couple of projects.

The first known case of embankment of waste containment is the one already mentioned and dated 1986 (Modena landfill, Cazzuffi et al., 1993). It consisted in an embankment, $5.00 \mathrm{~m}$ high, with face inclined at $45^{\circ}$ on the external side of the landfill and at $55^{\circ}$ in the internal side; the embankment was constructed over the waste, and stability analysis was taking into account also settlements benath the embankment.

More recently (Cowland, 2007) a 35m-high and $340 \mathrm{~m}$ long embankment bridging two hilltops was constructed to retain wastes of the North East New Territories (NENT) Landfill in Hong Kong. Both the faces were inclined at $68^{\circ}$ on the horizontal; the external side was divided in steps $7.50 \mathrm{~m}$ high separated by berms $2.00 \mathrm{~m}$ wide, and was constructed with a fire resistance facing; the internal face was divided in steps $12.00 \mathrm{~m}$ high, with the same type of berms, and was covered with the lining system. Stability analysis on both sides of the reinforced embankment before filling were studied, as well as overall stability with waste deposit against the internal face.

As shown in the cases here described, the presence of the geogrid allows to construct embankments and em-

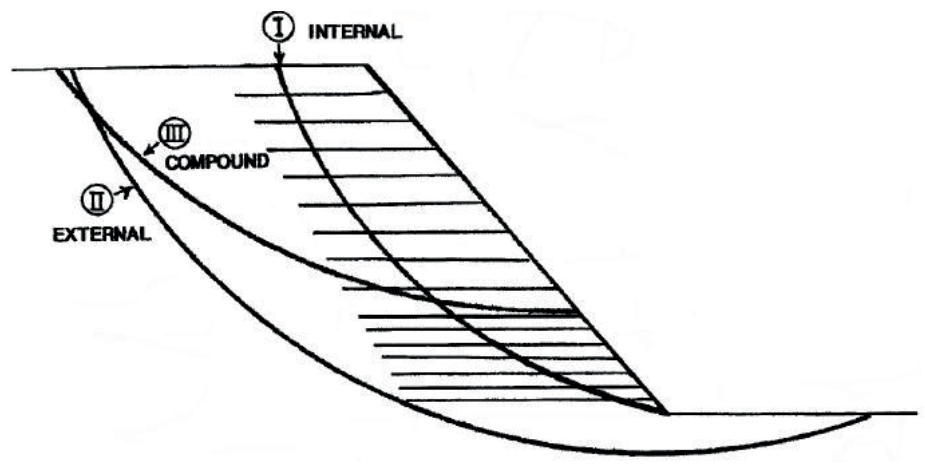

FIGURE 1: Failure modes for reinforced soil slopes. 

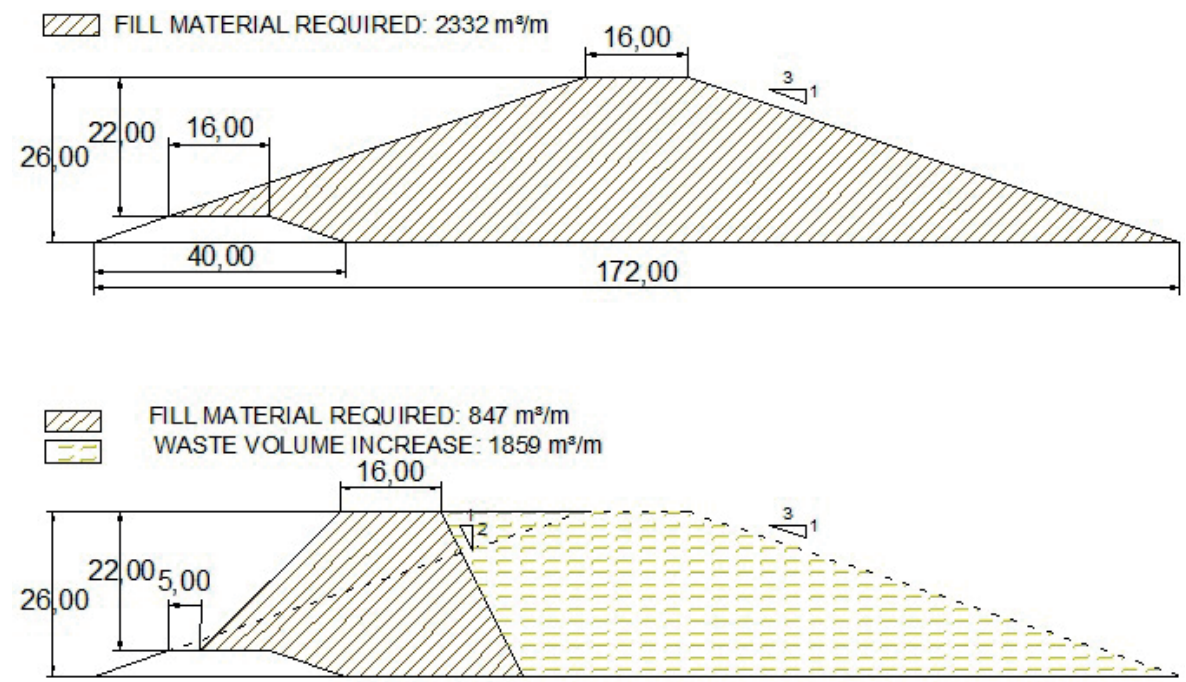

FIGURE 2: Comparison between a traditional shallow embankment and a geogrid reinforced steep slopes embankment.

bankments with an angle, both in the internal and the external face, much steeper respect to the unreinforced case, allowing for a reduction in the volume (and the cost) of fill material necessary and in the meantime an increase of the available volume. An example where a traditional embankment with very shallow slopes is compared to a geogrid reinforced embankment, is shown in Figure 2.

\section{EXAMPLE OF GEOGRID REINFORCED EXAM- PLES TO INCREASE THE AVAILABLE VOLUME}

\subsection{Teglio Landfill, Valtellina, Italy}

The landfill was constructed in the late '90 in Valtellina Valley (Northern Italy), as described by Montanelli et al., 1997. This valley is characterised by the presence of an important alluvial deposit, with different characteristics below the river (where it is mainly gravel) or at the side of the river (where the alluvial deposit are made of gravel, sand, silty sand with intercalation of silty peat); close to the side of the valley, there is a transition area with slope debris and alluvial fans made of gravel or sandy gravel alluvial deposits. Due to lack of better available areas, the landfill had to be constructed over an area where all the previously described situations were encountered.

Seven continuous dynamic penetration tests with 51 $\mathrm{mm}$ cone (DPT) and two static penetration tests (CPT) were performed; grain size distribution, unit weight and Atterbergh limits were measured. The subsoil was found to be mainly sand; peat was limited to thin intercalation layers, while there were almost no clay layers. The soil, according to U.S.C.S., could be defined mainly as SM (silty sand).

The relative density, determined after the penetration tests (with all the required correction factors), was found to be around $70-80 \%$ for the top $9.00 \mathrm{~m}$, and $80-85 \%$ at a greater depth. Shear parameters were obtained from tests: a friction angle of $34^{\circ}$ was found in the upper $9 \mathrm{~m}$, while higher values $\left(36^{\circ}\right)$ were obtained at a greater depth.

Global stability analysis was performed on the whole landfill body. Both Fellenius and Janbu method were used; the check was extended to circular surfaces passing through the toe of the first block and interesting the whole landfill, but also to circles passing through horizontal surfaces beneath the first embankment, and finally to circular surfaces completely within the reinforced blocks. Results of global stability analysis are shown in Figure 3.

The front embankments necessary to provide the confinement to the wastes were built using monoriented HDPE geogrids. Movable formworks were used for the construction, in order to avoid any possible damage to the HDPE geomembrane used for waterproofing the side slopes. The formworks were made of scaffolding tubes with timber boards: the formworks were placed near the edge of the slope, then a mono-oriented geogrid was placed; a bi-oriented geogrid was placed at the edge of the slope, leaving an edge outside the movable formwork. After laying down and compacting the fill soil, the bi-oriented geogrid was wrapped around the face and then the formwork was extracted (with a back-hoe) and used for the following reinforcement layer.The layout and some details of this application are described in Figure 4, Figure 5 and Figure 6.

\subsection{Genna Luas, Sardinia, Italy}

Genna Luas was a mine for metal sulfurs (zinc, copper, lead, and nickel) operating till the 80 's. The need to collect residual hazardous wastes of an industrial site created in the area, were making it necessary to create a landfill in the dismissed mine. In order to have the maximum volume the use of a single embankment at the base was immediately disregarded, and it was substituted by a series of 10 embankments, with slopes inclined at $27^{\circ}$ and $35^{\circ}$. This solution was superseded after the construction of the first 3 embankments, and the top 7 embankments were built with steep slopes. The increase in the volume available for wastes per running meter of superimposed embankments was over $1400 \mathrm{~m}^{3} / \mathrm{m}$, and the saving in fill material was $150 \mathrm{~m}^{3} / \mathrm{m}$. From 2006 to 2019 a total number of 7 superimposed reinforced embankments (total height of $36 \mathrm{~m}$ ) have been constructed. Figure 7 shows a comparison between the two proposals, enhancing the volume increase. 


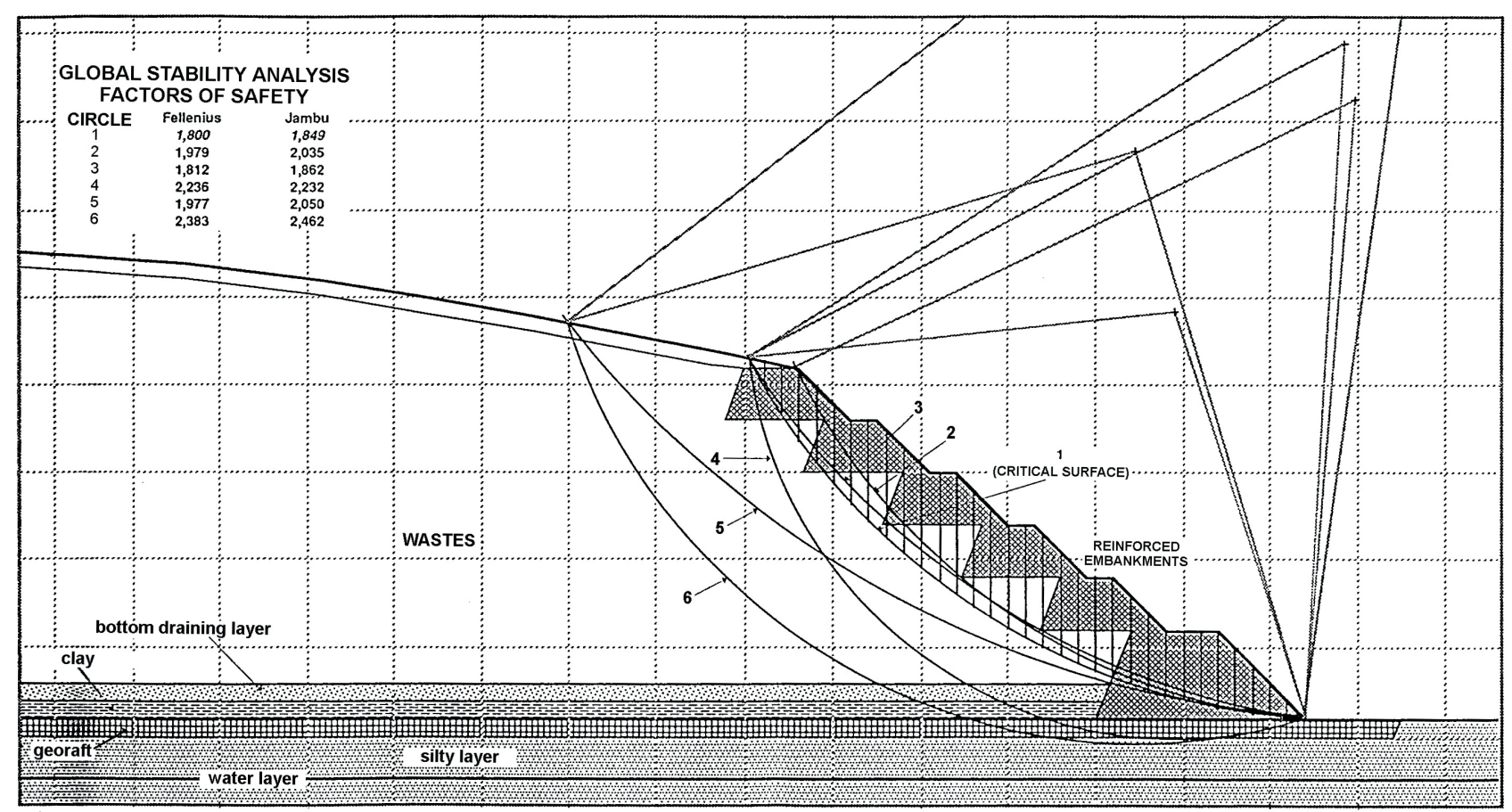

FIGURE 3: Teglio landfill stability analysis.

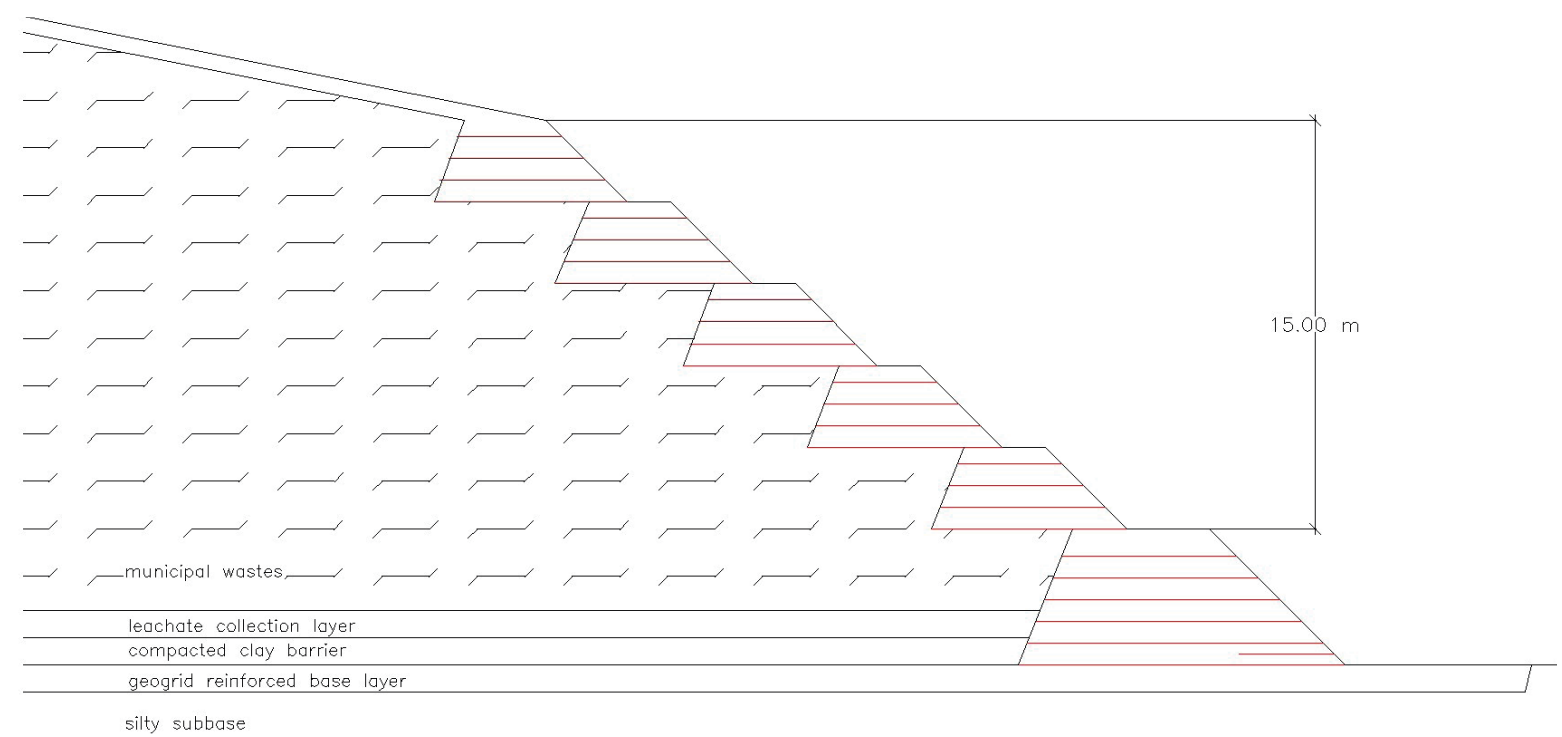

FIGURE 4: Teglio landfill layout.

The stability of the embankments has been studied before building every structure; the local stability of every embankment as well as the global stability of the whole landfill up to the level studied were evaluated. The different degree of compaction and consolidation of the wastes, that were showing a different behaviour in the short term and in the long term, was evaluated.

From geotechnical analysis, in the short term the material was purely frictional with $\Phi$ equal to $38^{\circ}$, while after consolidation it was turning into a cemented block, characterized by an undrained cohesion $\mathrm{cu}$, measured from unconfined compressive test, equal to $2 \mathrm{MPa}$.

The fill material for the rienforced embankment was a sandy gravel coming from a nearby area characteirsed by a friction angle of $38^{\circ}$ and a compacted unit weight of 19.5 $\mathrm{kN} / \mathrm{m}^{3}$.

A limit equilibrium analyses (global stability as well as translational analyses on every geogrid layer) have been performed. The results both in the short and in the long term were well above the requirements of the regulations; Figure 8 shows the stability analysis of the landfill in the long term.

Details of this application are described in Figure 9, Figure 10 and Figure 11, while Figure 12 shows an aerial view during the construction of the top embankment with filling operation. 


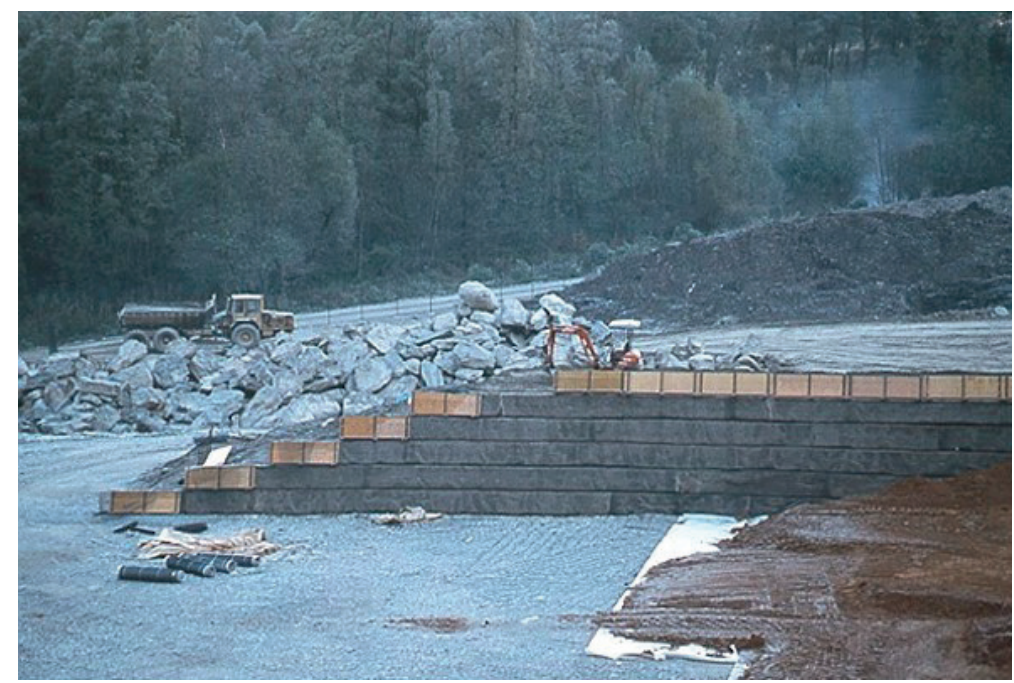

FIGURE 5: Teglio landfill; internal side of the landfill (compacted clay layer can be seen).

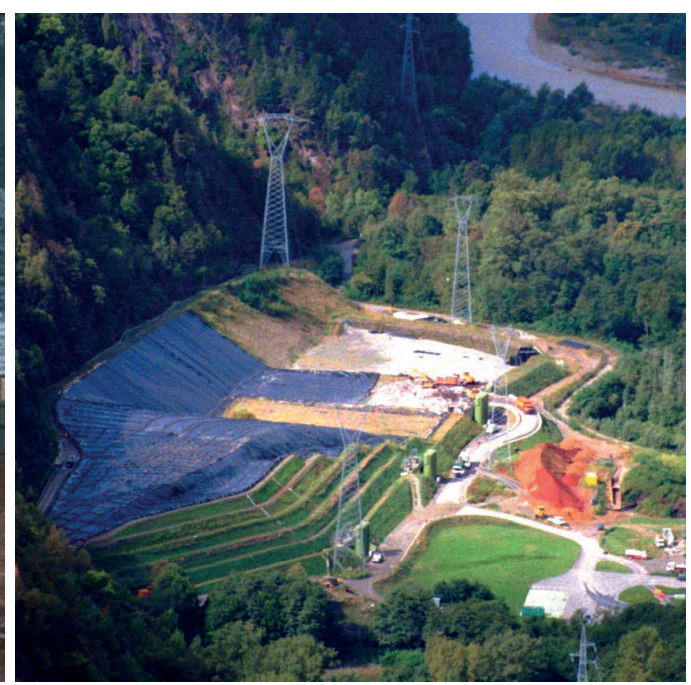

FIGURE 6: Teglio landfill; aerial view.

\section{original solution}

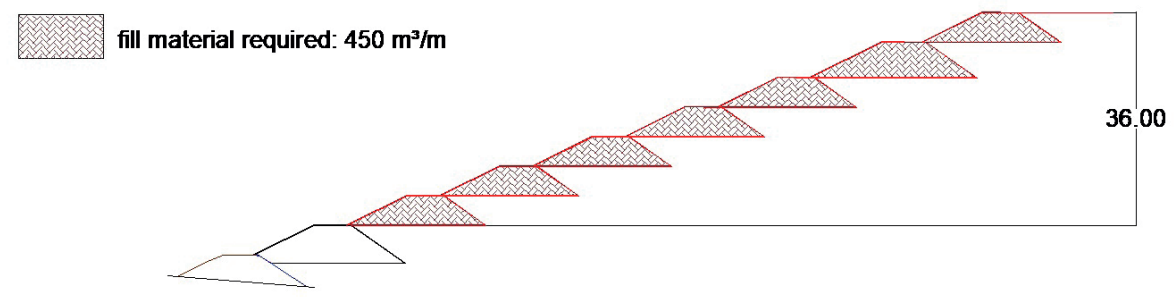

\section{final solution}

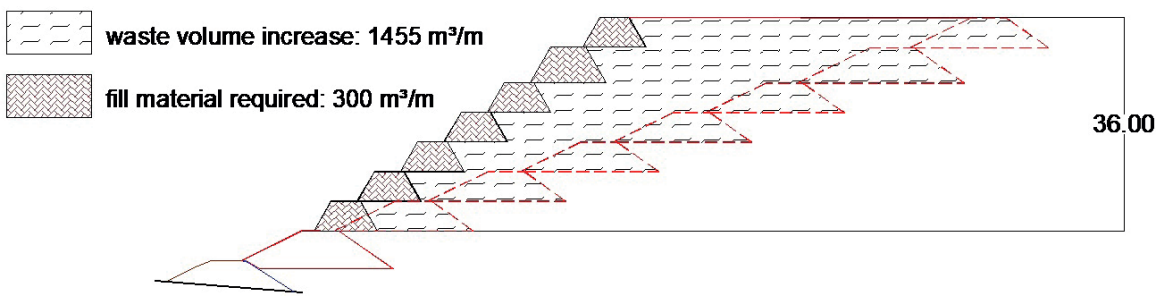

FIGURE 7: Comparison of traditional and reinforced embankments in Genna Luas landfill.

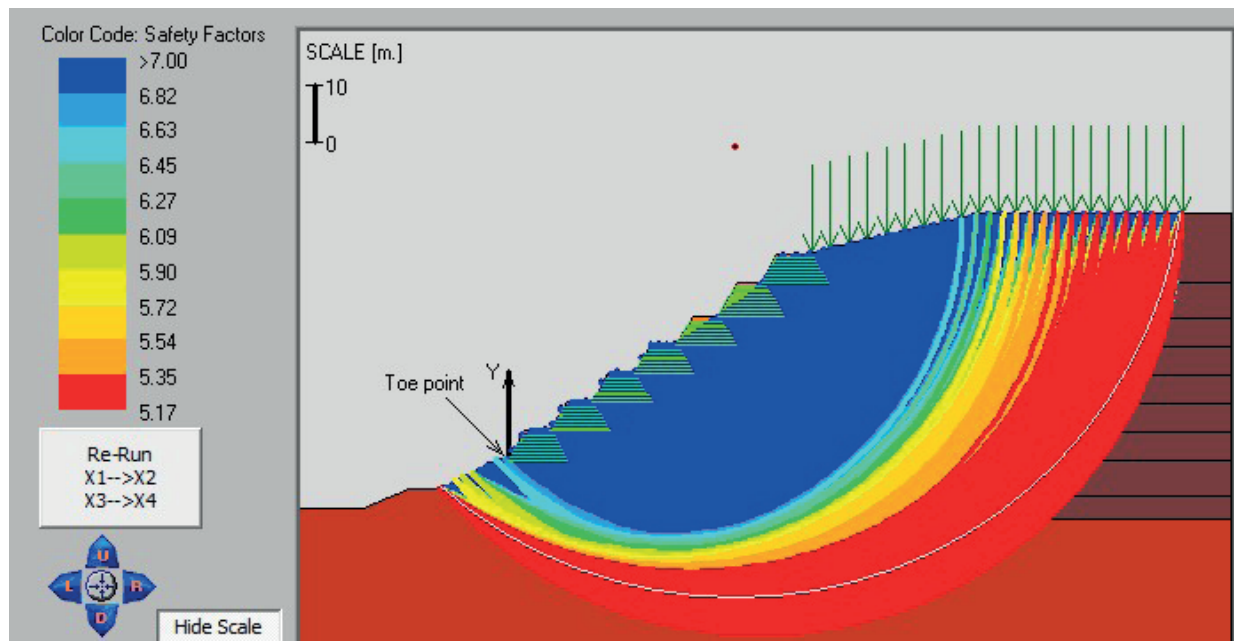

FIGURE 8: Long term global stability analysis results for the whole landfill. 


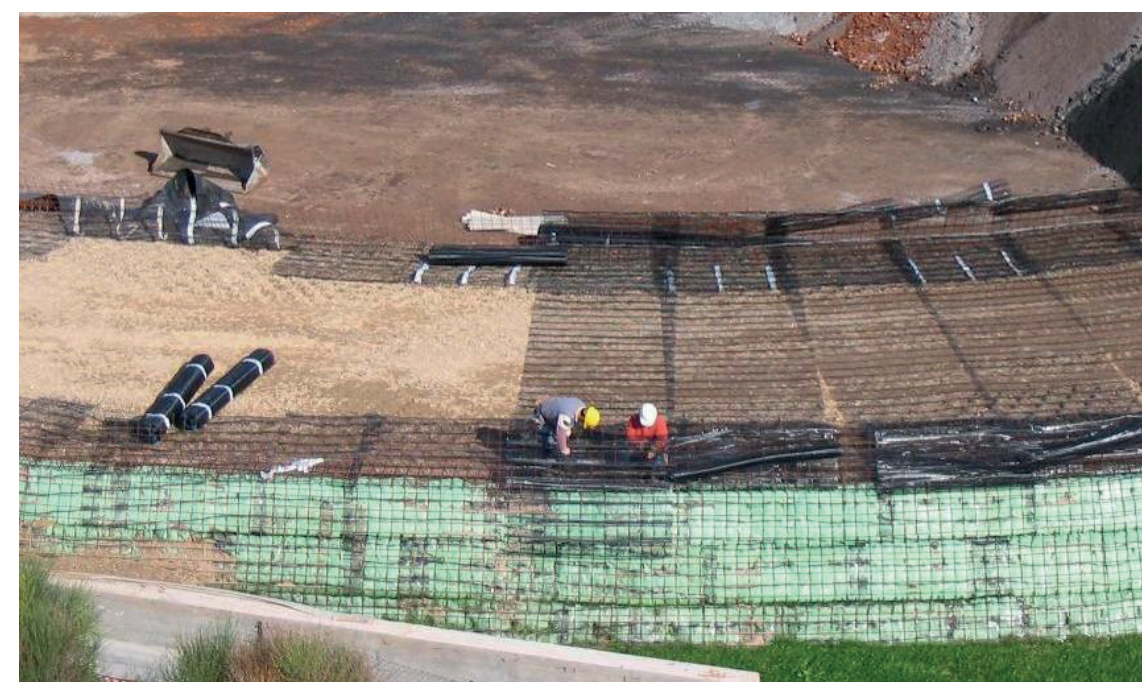

FIGURE 9: Installation of geogrids in Genna Luas landfill.

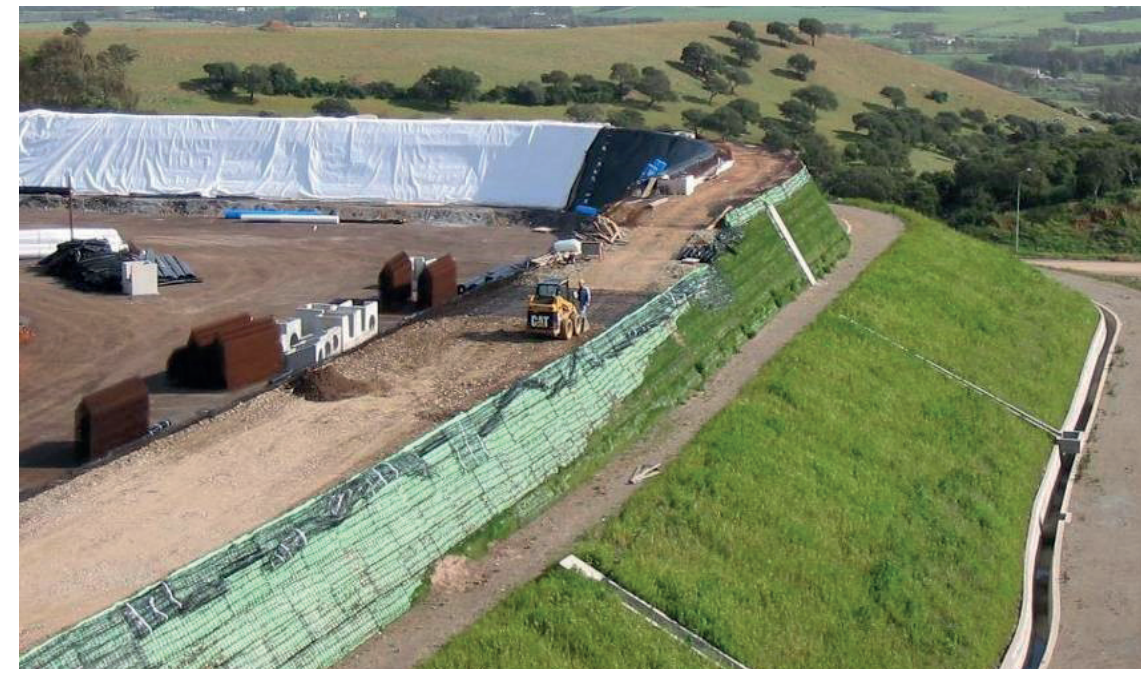

FIGURE 10: Installation of waterproofing liner in the internal side.

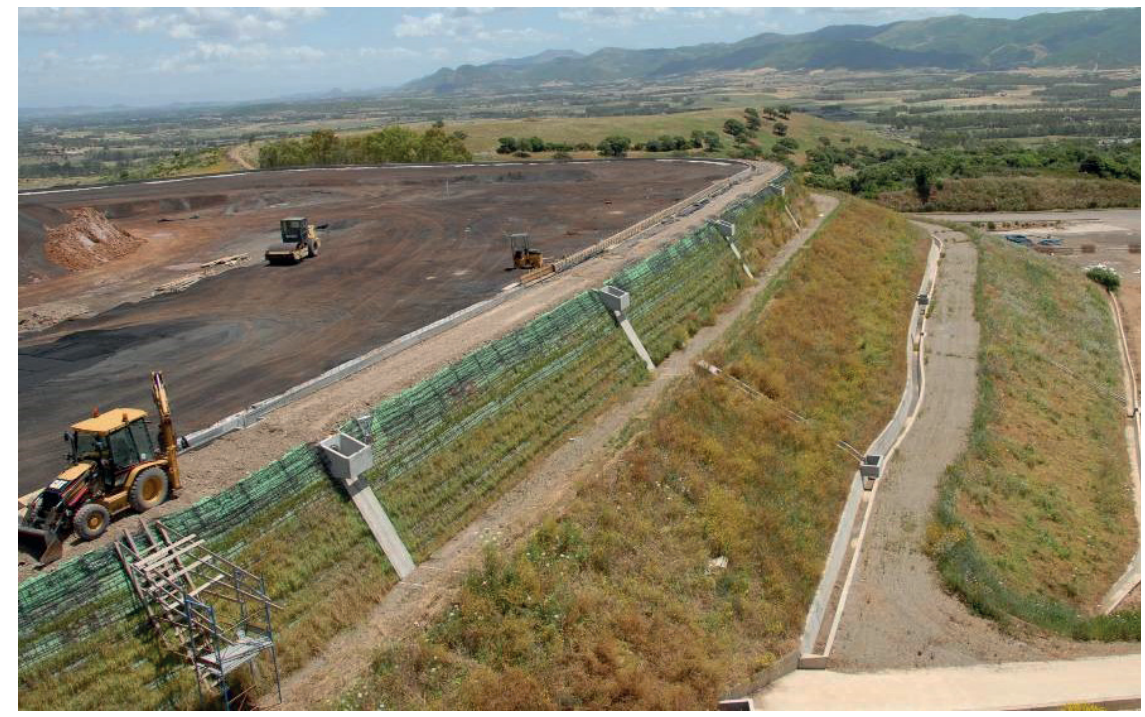

FIGURE 11: Filling phase with ashes. 


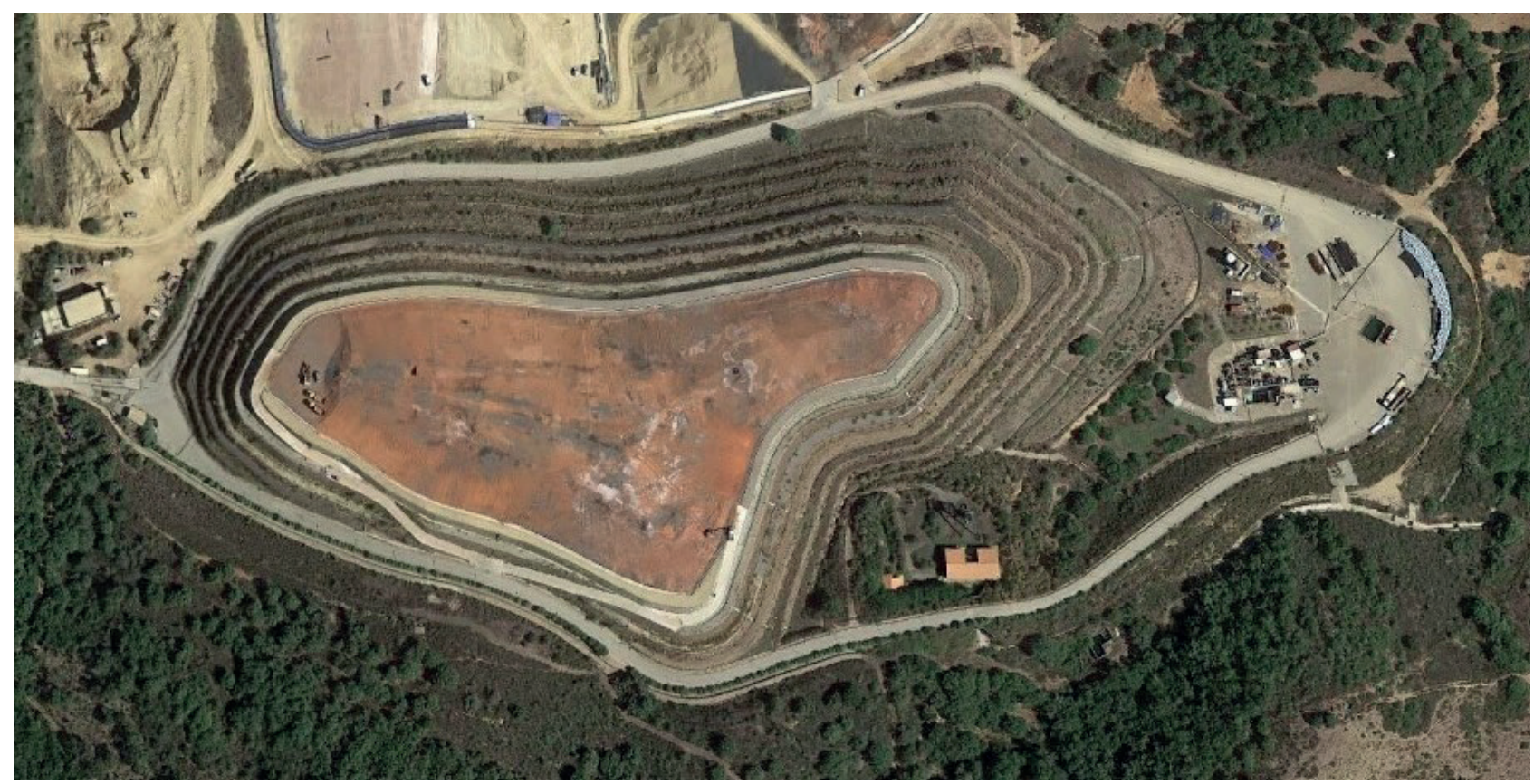

FIGURE 12: Aerial view during construction of the top embankment.

\section{CONCLUSIONS}

The use of steep slopes is getting more and more widespread in European, Asian and American countries for the construction of landfills, as it gives important advantages in terms of available volume, in terms of stability safety of the embankment and also in terms of costs. A proper selection of the type of geosynthetic should be done, considering the environment's boundary conditions typical of landfills. Successful examples of this technique, almost 25 years old, are present in Italy and in several other European, Asian and North American countries.

The solution of steep embankments allows to reduce the volume (and the cost) of fill material necessary and to increase the available volume for waste.

The use of geogrid reinforced steep slope guarantees important advantages as the composite material (fill + geogrids) has better compressive and shear behavior when compared to an unreinforced soil. These improvements give to a geogrid reinforced embankment the possibility to absorb quite large deformation without losing the integrity and functionality of the structure.

This aspect is particularly important when, rather than having a single embankment, a series of smaller size superimposed embankments are constructed.

This choice gives further advantages: the amount of fill material is reduced and the available landfill volume is further increased; it is possible to lay down the geosynthetics drainage and barrier systems only on a small portion of the landfill front face and not on the whole face, reducing the possible weathering of the geosynthetics and distributing according with the filling process of the landfill (and hence with the earnings by the owner) the cost of the purchase and installation.

The only possible minus of such solution could be the settlements under the portion of embankment directly laying over the wastes, particularly when the municipal wastes are present. The possibility to lay a large part of the bund directly upon the lower one, and the capability of the structure to absorb quite important strains and settlements without losing the functionality, allows somehow to overpass this problem.

\section{REFERENCES}

Cancelli, A., Cazzuffi, D. 1994. Environmental aspects of geosynthetics applications in landfills and dams, Proceedings of the Fifth International Conference on Geotextiles, Geomembranes and Related Products, Singapore, September, Keynote Lecture 2, Preprint Volume on Special Lecture and Keynote Lectures, 55-95.

Cazzuffi, D., Pagotto A., Rimoldi, P. 1993. The Modena geogrid-reinforced embankment founded on urban wastes: measurements of settlements, tensile forces and strains. Proceedings International Symposium on Soil Reinforcement, Paris, November, Presses de I'Ecole Nationale des Ponts et Chaussées, 431-448.

Cazzuffi, D., Recalcati, P. 2018. Recent developments on the use of drainage geocomposites in capping systems. Detritus - Multidisciplinary Journal for Waste Resources \& Residues, CISA Publisher, Vol. 3, 93-99.

Cowland, J.W. 2007. Use of geogrid reinforcement to increase landfill capacity. Proceedings Sardinia 2007, Eleventh International Waste Management and Landfill Symposium. S. Margherita di Pula Cagliari, Italy; 1 - 5.

Grossule, V., Stegmann, R. 2020. Problems in traditional landfilling and proposals for solution based on sustainability. Detritus, Vol. 12, 7891, doi: 10.31025/2611-4135/2020.14000.

Montanelli, F., Recalcati, P., Rimoldi, P. 1997. The extensive use of geosynthetics for the environmental protection in the construction of landfills in Italy: a state-of-the-art. Proceedings Geosynthetics Asia '97 Conference, Bangalore, India, November, Vol. 2, 117-124. 